\title{
The stringent response in Myxococcus xanthus is regulated by SocE and the CsgA C-signaling protein
}

\author{
Eugene W. Crawford, Jr. and Lawrence J. Shimkets ${ }^{1}$ \\ Department of Microbiology, University of Georgia, Athens Georgia 30602-2605 USA
}

\begin{abstract}
Myхососcus xanthus fruiting body development is induced by amino acid limitation. The decision to grow or develop is established by the RelA-dependent stringent response and A-signaling. We identified two new members of this regulatory hierarchy, socE and the C-signaling gene $\operatorname{csg} A$. SocE depletion arrests growth and induces sporulation under conditions that normally favor growth as well as curtailing DNA and stable RNA synthesis, inhibiting cell elongation, and inducing accumulations of the stringent nucleotides ppGpp and pppGpp [(p)ppGpp]. This system separates C-signaling, which does not occur under these conditions, from CsgA enzyme activity. Amino acid substitutions in the CsgA coenzyme binding pocket or catalytic site eliminate growth arrest. relA mutation also eliminates growth arrest. Eleven pseudorevertants selected for growth following SocE depletion contained mutations in $\operatorname{csgA}$ or relA. These results suggest that CsgA induces the stringent response and while SocE inhibits it. Unlike the $\operatorname{csg} A$ mutant, wild-type and $\operatorname{soc} E \operatorname{csg} A$ cells maintained high levels of (p)ppGpp throughout development. We suggest that CsgA maintains growth arrest throughout development to divert carbon from A-signaling and other sources into developmental macromolecular synthesis.
\end{abstract}

[Key Words: M. xanthus; development; fruiting body formation; cell-cell signaling; growth control; stringent response]

Received December 3, 1999; revised version accepted January 18, 2000.

Fruiting body development of Myxococcus xanthus is induced when amino acid depletion forces the cells to decide whether to grow or develop. Central to the decision is the stringent response, which shares many features with that of Escherichia coli (for review, see Cashel et al. 1996). When ribosomes stall because of lack of charged tRNA, the ribosome-associated protein RelA synthesizes guanosine-5' -diphosphate- $3^{\prime}$-diphosphate (ppGpp) and guanosine-5'-triphosphate- $3^{\prime}$-diphosphate (pppGpp) (Harris et al. 1998; Manoil and Kaiser 1980b, 1980c), collectively abbreviated (p)ppGpp. Fruiting body development is also regulated by at least five extracellular signals, A, B, C, D, and E (Hagen et al. 1978; Downard et al. 1993). Elimination of any signal disrupts development within the first $6 \mathrm{hr}$ and inhibits fruiting body morphogenesis, spore differentiation, and developmental gene expression (for review, see Dworkin 1996; Shimkets 1999).

The stringent response activates A-signaling (for review, see Kaiser 1996; Plamann and Kaplan 1999), which begins with the secretion of proteases that hydrolyze cell surface proteins to generate amino acids (Kuspa et al. 1992; Plamann et al. 1992). Because Myxococcus cells

${ }^{1}$ Corresponding author.

E-MAIL shimkets@arches.uga.edu; FAX (706) 542-2674. themselves are the protease substrates, the amino acid concentration rises in direct proportion to cell density. Several of these amino acids serve as a quorum signal. Having ascertained that a quorum of starved cells is available, development continues. However, a potential problem emerges. The amino acids generated by A-signal proteases reach an extracellular concentration high enough to restore growth. They also provide a limited resource to fuel development. So the cell must change its physiology to funnel these amino acids to development rather than growth. The work described in this paper suggests that the C-signaling protein CsgA and the SocE protein help divert the carbon flow into developmental proteins by maintaining a stringent response even in the presence of A-signal amino acids.

The only known member of the C-signaling system is CsgA (for review, see Shimkets and Kaiser 1999). Addition of CsgA to buffer on top of $\operatorname{csg} A$ cells restores fruiting body formation and developmental gene expression (Kim and Kaiser 1990a, 1991). However, CsgA is a member of the short chain alcohol dehydrogenase family that uses the coenzyme NAD $(\mathrm{P})(\mathrm{H})$ (Lee et al. 1995). The proposed catalytic activity may be intracellular, as it is not clear that there is a pool of extracellular coenzyme. To complicate matters, CsgA also has a role in motility. It is essential for rippling, a multicellular behavior in which 
cells move in rhythmic oscillations (Shimkets and Kaiser 1982a; Sager and Kaiser 1994) and activates a sensory transduction pathway, Frizzy, that is structurally and functionally similar to the chemotaxis system of enteric bacteria (Sogaard-Anderson and Kaiser 1996). The role of the CsgA enzyme activity in these processes remains unknown, as does the chemical nature of the substrate.

In an attempt to define the biochemical function(s) of CsgA more clearly, Rhie and Shimkets (1989) isolated suppressor mutations in which the developmental requirement for CsgA has been bypassed. The socE537 mutation is a transposon insertion that results in loss of SOCE function yet restores development to $\operatorname{csg} A$ null mutants without restoring C-signaling (Rhie and Shimkets 1989; E.W. Crawford and L.J. Shimkets, in prep.). SocE is a highly basic protein with little similarity to proteins in sequence databases (E.W. Crawford and L.J. Shimkets, in prep.). Attempts to transfer the $\operatorname{soc} E$ null allele to $\operatorname{csg} A^{+}$ strains failed, suggesting that $\mathrm{SocE}$ is essential for growth in $\operatorname{csg} A^{+}$cells (E.W. Crawford and L.J. Shimkets, in prep.). In this work we placed SOcE under control of a light-inducible promoter and discovered that SocE depletion arrests growth and induces sporulation and a stringent response, even in the presence of amino acids, provided functional copies of $\operatorname{csg} A$ and $\operatorname{rel} A$ are present. This system allows the putative CsgA enzyme activity to be isolated from C-signaling and studied independently. The results suggest that CsgA and SocE have opposing roles in the decision to grow or develop through a modified stringent response.

\section{Results}

SocE is required for growth of $\mathrm{csg}^{+}$cells

The original SOcE mutation was a Tn5 insertion that suppressed the $\operatorname{csg} A$ developmental defect without restoring C-signaling. Attempts to move this mutation into a $\operatorname{csg} A^{+}$mutant were unsuccessful (E.W. Crawford and L.J. Shimkets, in prep.). To determine whether a socE mutation is lethal in $\operatorname{csg} A^{+}$cells we expressed $\operatorname{soc} E$ using the $M$. xanthus light-inducible promoter pcarQRS (abbreviated phv). This promoter is inactive in the dark and becomes highly active in blue light (Hodgson 1993). A FspI-NcoI fragment carrying the 5 ' portion of $s O c E$, which does not encode essential carboxyl-terminal amino acid sequences (E.W. Crawford and L.J. Shimkets, in prep.) was inserted downstream of phv to create pGC28. The phv-socE construct was electroporated into wild-type $M$. xanthus cells in the presence of light to stimulate expression of SOCE. Homologous recombination between the wild-type socE allele and the light-inducible construct produced a merodiploid, LS2125, containing a $3^{\prime}$ deletion of the native copy of $S O c E$, under control of its own promoter, and a light-inducible fulllength copy of SocE. Southern blotting confirmed the presence of the predicted recombination event /data not shown).

Expression of phv-socE was examined in the light and the dark. LS2125 was cultured in CYE broth in the light.
When cells reached early log phase one of two replicate cultures was wrapped in foil to block the light, terminating SOcE expression. SocE mRNA was quantified by hybridization with a probe complementary to the $3^{\prime}$ NcoI-HindIII fragment of SocE. By $1 \mathrm{hr}$ after the shift to the dark SocE mRNA was undetectable, whereas the level of SocE mRNA in light-grown cultures remained constant (data not shown).

The phenotype of SocE-depleted cells was compared under light and dark conditions using a similar approach. Aliquots were removed for cell and spore quantitation over $216 \mathrm{hr}$ (Fig. 1). Growth of LS2125 ceased 12-15 hr ( 2.5 generations) after elimination of SocE expression in spite of the presence of excess nutrients. The cells undergo 2.5 doublings before growth arrest, which would reduce the SocE concentration about sixfold in the absence of protein turnover. Dark-grown cells began to sporulate at $144 \mathrm{hr}$, and by $168 \mathrm{hr}$ nearly all cells had become spherical, refractile spores. The addition of light to SocE-depleted cells at any point prior to sporulation allowed growth to resume (data not shown). In contrast, LS2125 cells incubated in the light continued to grow until they reached stationary phase at $\sim 36 \mathrm{hr}$ and did not form spores through the course of the experiment (168

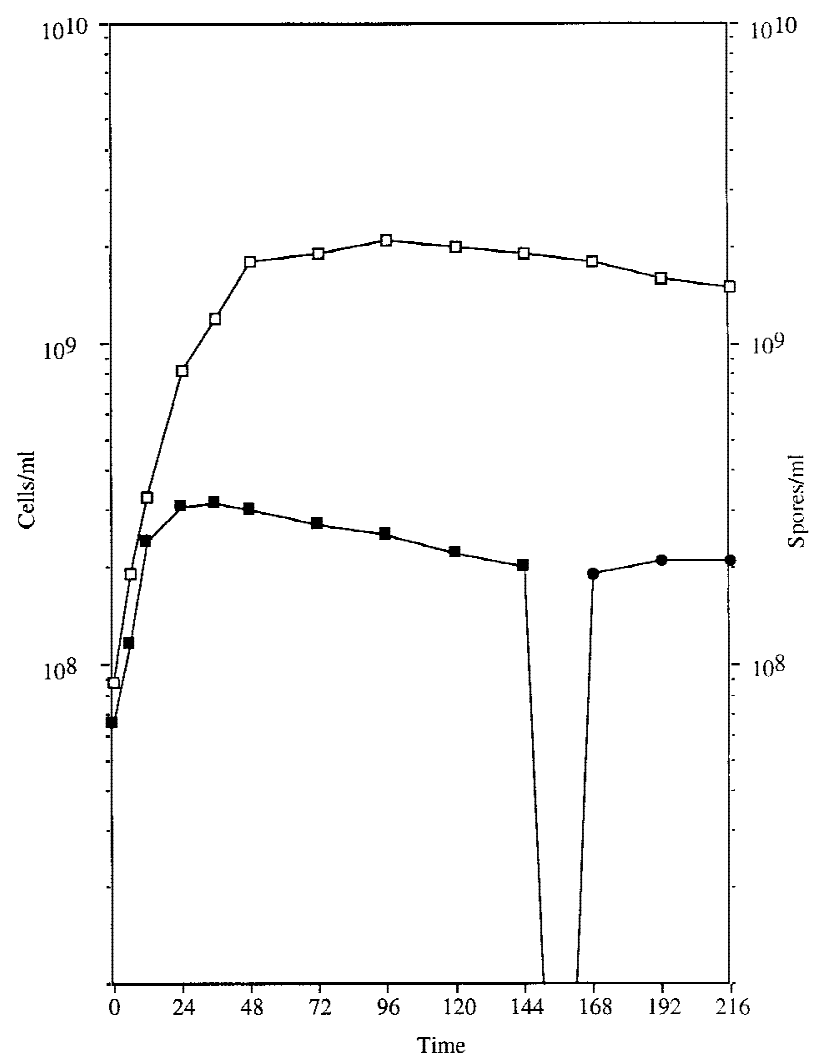

Figure 1. Effect of $\operatorname{Soc} E$ depletion on cell growth. At time 0 light-grown cultures of LS2125 cells were shifted to darkness (solid symbols) or allowed to continue growing in the light (open symbols). Cell number (squares) and spore number (circles) were determined by direct counts. After $\sim 2.5$ generations the SocEdepleted cells ceased growing, and by $168 \mathrm{hr}$ most had sporulated. 
hr). Wild-type cells also exhibited normal growth and did not form spores in the light or the dark under these conditions (data not shown).

During fruiting body development only a fraction of the cells become spores. About $15 \%$ of the cells remain outside the fruiting bodies, becoming peripheral rods (O'Connor and Zusman 1991b). O'Connor and Zusman (1991a) have proposed that peripheral rods emerge because of the secretion of aggregation and sporulation inhibitors. An even larger portion of the population dies during fruiting body development (Wireman and Dworkin 1975). These alternate fates are bypassed in this SocE-depletion assay, as virtually all of the cells differentiate into spores. However, the spore yield during fruiting body development of SocE-depleted cells is comparable to that of wild-type and $\operatorname{soc} E \operatorname{csg} A$ mutants, suggesting that suppression of these alternate developmental fates is largely due to the environmental conditions of the assay.

\section{Spore structure}

The formation of myxospores in liquid growth medium is reminiscent of a technique for artificially inducing sporulation. Dworkin and Gibson (1964) discovered that the addition of $0.5 \mathrm{M}$ glycerol to growing $M$. xanthus cells induces sporulation in the absence of starvation and multicellular development. Since this discovery it has been demonstrated that glycerol-induced spores differ from fruiting body spores in a number of ways: (1) The rate of respiration is higher in glycerol-induced spores than it is in fruiting body spores (Dworkin and Niederpruem 1964); (2) glycerol-induced spores lose refractility when incubated in phosphate buffer, unlike fruiting body spores (Ramsey and Dworkin 1968); (3) glycerolinduced spores have a thin spore coat that is deficient in spore coat proteins C (McCleary et al. 1991), S (Inouye et al. 1979), and U (Gollop et al 1991); and (4) glycerolinduced spores lack the polyphosphate storage particles formed by protein $\mathrm{W}$ in fruiting body spores (Otani et al. 1998).

Transmission electron microscopy was used to determine if the spores produced by SocE depletion were more similar to glycerol-type or fruiting body-type spores. The spores of SocE-depleted LS2125 were similar to wild-type fruiting body spores, having thick spore coats and protein $\mathrm{W}$ inclusions (data not shown). This approach represents the first description of a method to obtain fruiting body-like spores in liquid growth media. LS2125 spores were unable to germinate in the light or dark, on CYE agar or in CYE broth (data not shown). Perhaps SocE is necessary to initiate germination and $\mathrm{p} h v$ cannot be activated by light in the dormant spore.

\section{Macromolecular synthesis during growth arrest}

Measurement of cell length affords an easy assessment of progress through the cell division cycle. Newly divided cells are short and nearly double in length during the cell cycle. Septa appear at 0.90 generation, and separation occurs at 1.0 generation. Growth-arrested cells varied in length from short nascent cells to long septating cells (data not shown). Most cells were within the normal range of lengths and widths. Furthermore, newly arrested cells exhibited a similar range of sizes to those that had been arrested for several days. It appears that growth is not arrested at a single point in the cell division cycle but that cell elongation ceases.

Cells synthesize RNA throughout the cell division cycle (Zusman and Rosenberg 1971). RNA synthesis was assessed by incorporation of $\left[{ }^{3} \mathrm{H}\right]$ uridine into trichloroacetic acid (TCA)-insoluble material. After the shift to dark, LS2 125 continued to grow and incorporate $\left[{ }^{3} \mathrm{H}\right]$ uridine in parallel with wild-type DK1622 up to $15 \mathrm{hr}$, ceased growth, and reduced RNA synthesis (Fig. 2A). Because stable RNA accounts for $~ 80 \%$ of the total RNA and sporulation-specific genes become active after growth cessation, it is likely that the decline in transcription primarily reflects a decline in stable RNA synthesis rather than a complete inhibition of RNA production. At least some development-specific, CsgA-dependent genes are transcribed under these conditions. SLS234 is expressed at levels comparable to those observed during fruiting body development. $\Omega \mathrm{DK} 4531$ is expressed at $35 \%$ the level observed during fruiting body development, and $\Omega \mathrm{DK} 4435$ is expressed at $\sim 13 \%$ (data not shown). These results suggest that transcription under these conditions is highly selective.

Chromosome replication extends from 0.02 to 0.81
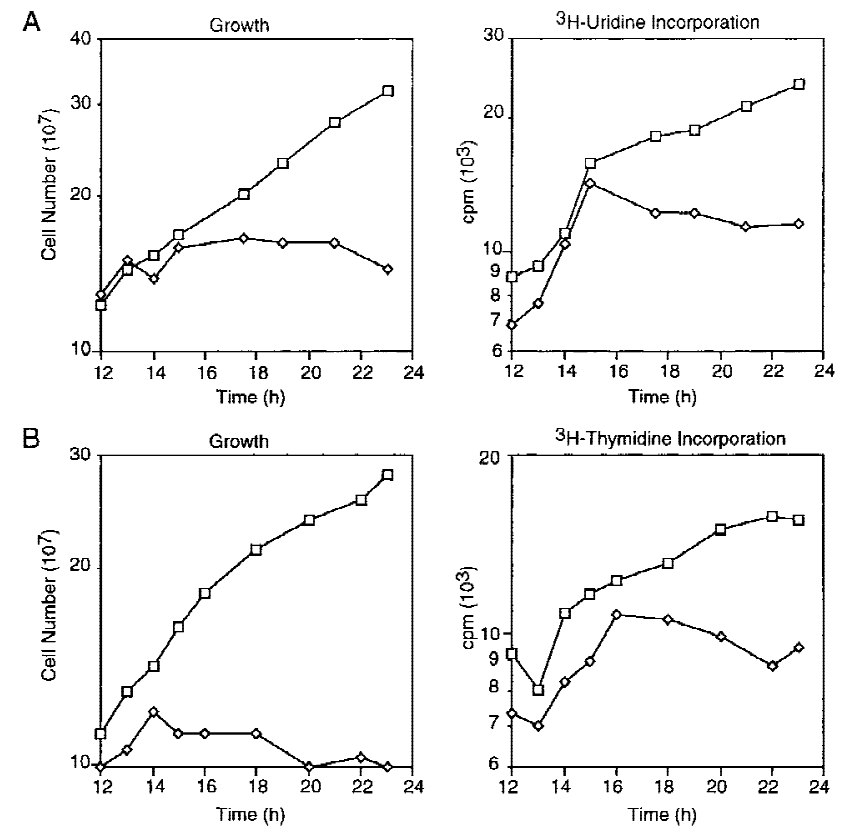

Figure 2. Nucleic acid synthesis following SocE depletion. At time 0 light-grown cultures were transferred to the dark and incubated. DK1622 (wild type, $\square$ ); LS2125 (phv-socE, $\diamond) .(A)$ Growth (left) and $\left[{ }^{3} \mathrm{H}\right]$-uridine incorporation into RNA (right). (B) Growth (left) and $\left[{ }^{3} \mathrm{H}\right]$ thymidine incorporation into DNA (right). 
generations covering the majority of the cell cycle (Zusman and Rosenberg 1970). Incorporation of $\left[{ }^{3} \mathrm{H}\right]$ thymidine into TCA-insoluble material was used to assess DNA synthesis. Growth and $\left[{ }^{3} \mathrm{H}\right]$ thymidine incorporation by LS2125 cells incubated in the dark paralleled that of DK1622 up until $\sim 16 \mathrm{hr}$, at which time growth of LS2125 ceased and $\left[{ }^{3} \mathrm{H}\right]$ thymidine incorporation declined (Fig. 2B). These results demonstrate that SocE depletion inhibits both DNA and RNA synthesis.

\section{SocE depletion leads to an increase in (p)ppGpp levels}

Accumulation of (p)ppGpp is correlated with a decline in the growth rate, and inhibition of DNA and stable RNA synthesis in E. coli (for review, see Cashel et al. 1996). Two enzymes can synthesize (p)ppGpp-RelA and SpoT. RelA is ribosome associated and has only synthetic activity. When E. coli is starved for amino acids, uncharged tRNA causes translational pausing, which stimulates phosphorylation of GTP or GDP in a reaction that requires ATP, ribosomes, mRNA, RelA, and uncharged tRNA. SpoT has (p)ppGpp 3'-pyrophosphohydrolase activity in addition to synthetic activity that is not associated with ribosomes.

(p)ppGpp pools were measured to determine whether growth inhibition following SocE depletion is due to induction of the stringent response. LS2125 cells were grown in the light in CYE broth containing $\left[{ }^{32} \mathrm{P}\right]$ orthophosphate to label the pools to steady state. Labeled cultures were then diluted into identical ${ }^{32} \mathrm{P}$-containing CYE and placed in the light for continued growth or in the dark to eliminate ectopic socE expression. Aliquots were removed at regular intervals for $24 \mathrm{hr}$, and the guanine nucleotides separated by thin layer chromatography (TLC). Light-grown cells maintained a relatively constant level of GTP and low levels of (p)ppGpp (Fig. 3). GTP, ppGpp, and pppGpp pools were quantified and are relatively constant in light-grown cells in spite of the fact that the cells entered stationary phase (Fig. 4).

Following shift to the dark there is a dramatic increase
A

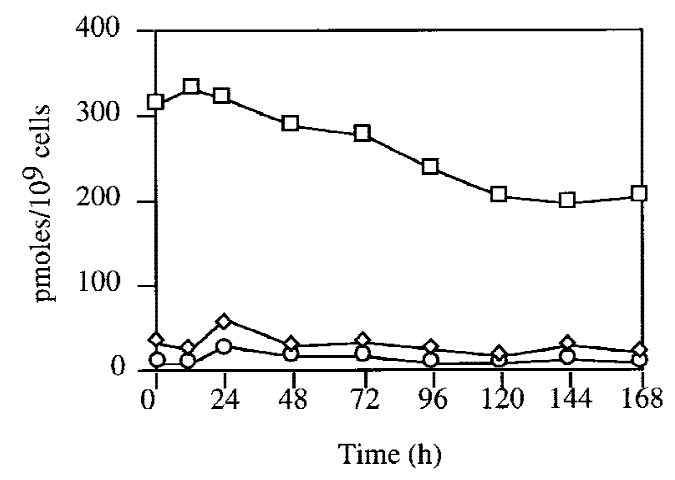

B

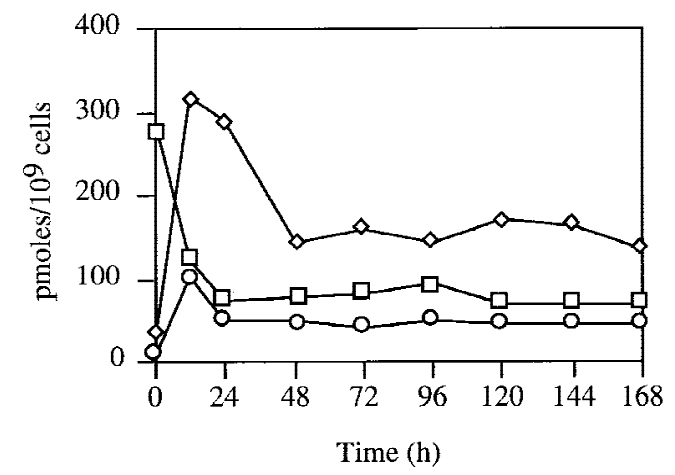

Figure 4. Guanine nucleotide pool sizes. LS2125 (phv-socE) was incubated in CYE containing $\left[{ }^{32} \mathrm{P}\right]$-orthophosphate in the light $(A)$ or dark $(B)$. Guanine nucleotide pools were extracted at the indicated times, separated by one-dimensional TLC, and quantified using a PhosphorImager $400 \mathrm{~S}$ and ImageQuant software. Nucleotide levels are expressed as pmoles of nucleotide per $10^{9}$ cells. ( $\left.\square\right)$, GTP; $(\diamond)$ ppGpp; (O) pppGpp.

in the ppGpp pool and a more modest increase in pppGpp (Fig. 3). Cells showed a marked increase in (p)ppGpp levels by $6 \mathrm{hr}$, and levels peaked at $12 \mathrm{hr}$ when macromo-

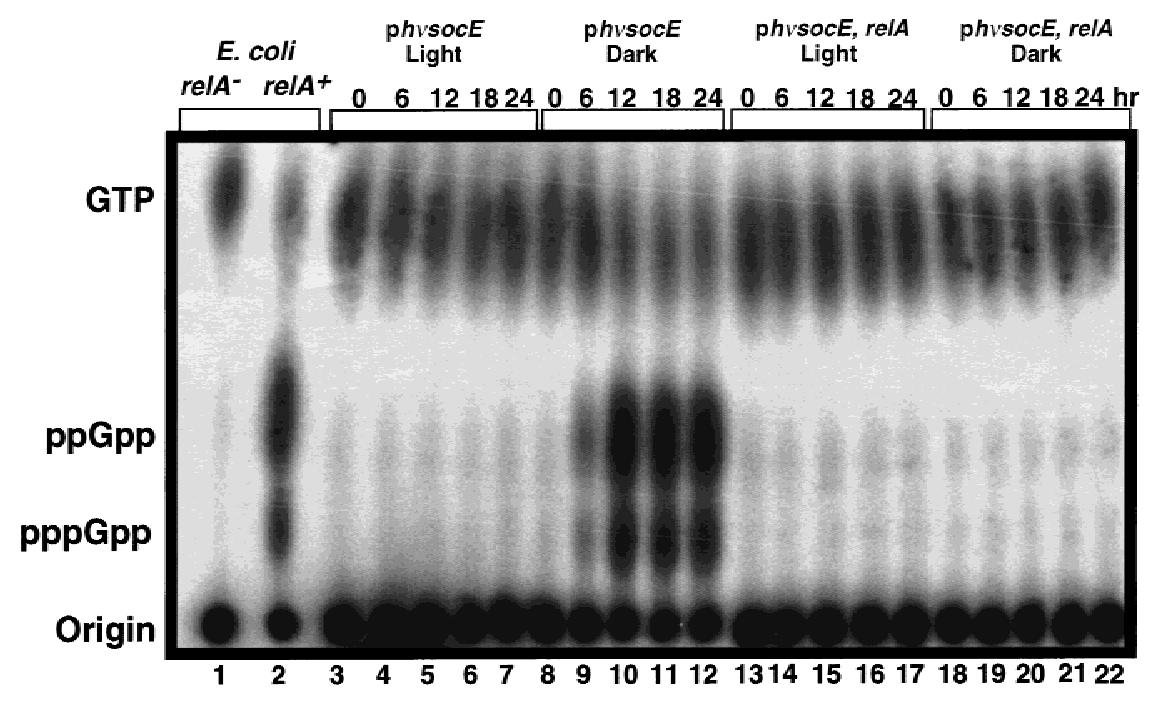

Figure 3. Measurement of the guanine nucleotide pools. phv-SOCE (LS2125) and phv-SocE, relA (LS2162) were grown in CYE containing ${ }^{32} \mathrm{P}$-orthophospate in the light or in the dark. The guanine nucleotide pools were extracted at the times indicated across the top (hr) and separated by one-dimensional TLC. Into each lane, $15,000 \mathrm{cpm}$ was loaded. (Left) Guanine nucleotides were identified by their $r_{f}$ values using starved E. coli relA (lane 1) and $r e l A^{+}$(lane 2) strains as controls. 
lecular synthesis declined (Fig. 4). Concomitant with this increases in the (p)ppGpp pool was a comparable decrease in the GTP pool. The pool sizes of ppGpp and pppGpp then decrease about two-fold but remain much higher than the levels seen in light-grown cells. The experiment was concluded at $168 \mathrm{hr}$ when sporulation begins because the spores are resistant to nucleotide extraction by this method.

To determine whether induction of the stringent nucleotides is essential for growth arrest, the light-inducible $S O c E$ construct was introduced into a strain containing a relA mutation (Harris et al.1998). The relA mutation prevented both growth inhibition and sporulation following SocE depletion (data not shown), as well as the accumulation of (p)ppGpp (Fig. 3). The RelA-dependent production of the stringent nucleotides in the SocE depletion assay is surprising, as the cells are present in a liquid medium with amino acid levels that could support a 10-fold increase in cell number (Fig. 1).

\section{(p)ppGpp synthesis is CsgA-dependent but $C$-signal independent}

The ppGpp pool sizes of $\operatorname{csg} A^{+}$SocE-depleted cells were compared with wild-type strain DK1622, a $\operatorname{csg} A$ socE double mutant (LS537), and a csgA mutant (LS523) $12 \mathrm{hr}$ after a shift to the dark. Synthesis of ppGpp was observed only in $\operatorname{csg} A^{+}$SocE-depleted cells and is correlated with growth arrest and sporulation (Table 1). These results argue that CsgA stimulates ppGpp synthesis in the absence of SocE.

It is unlikely that C-signaling occurs under these conditions, as the cells are dispersed at low cell density in liquid growth medium to prevent contact-dependent exchange of the C-signal. Furthermore, the growth medium is not conditioned by secretion of a chemical signal required for growth arrest or sporulation. At 0, 12, 24, 120,144 , and $168 \mathrm{hr}$ after transfer to the dark the LS2125 culture supernatant was filtered through 0.22 - $\mu \mathrm{m}$ filters. Light-grown LS2125 cells were resuspended in the conditioned medium. Cultures incubated in the presence of the conditioned media continued to grow unabated until stationary phase and sporulation did not occur. Those shifted to the dark showed no change in the number of cell divisions preceding growth arrest, the time to initia-

Table 1. Guanine nucleotide pool sizes

\begin{tabular}{lcrcc}
\hline & \multicolumn{2}{c}{ pmoles $/ 10^{9}$ cells } & & \\
\cline { 2 - 3 } Genotype & GTP & \multicolumn{1}{c}{ ppGpp } & Growth & Sporulation \\
\hline $\operatorname{csg}^{+} \operatorname{soc} E^{+}$ & $521 \pm 62$ & $38 \pm 21$ & + & - \\
$\operatorname{csg}^{-} \operatorname{soc} E^{+}$ & $506 \pm 73$ & $29 \pm 11$ & + & - \\
$\operatorname{csg}^{+} \operatorname{soc} E^{-a}$ & $103 \pm 18$ & $318 \pm 37$ & - & + \\
$\operatorname{csg}^{-} \operatorname{soc} E^{b}$ & $478 \pm 53$ & $43 \pm 14$ & + & -
\end{tabular}

${ }^{\mathrm{a} C e l l s}$ were made $\operatorname{soc} E^{-}$through the ectopic expression system, as transduction of $\operatorname{socE537}$ into $\operatorname{csg} A^{+}$cells was not possible.

${ }^{\mathrm{b} C e l l s}$ contained the SocE537 mutation. tion of sporulation, or the fraction of cells sporulating compared to control cultures. It appears then that Csignaling does not occur under these conditions.

One possibility is that the putative catalytic function of CsgA is intracellular where it induces the stringent response. In support of this idea, all $\operatorname{csg} A$ mutations that disrupt fruiting body development also prevent growth arrest and sporulation in response to SocE depletion, arguing for a direct relationship between the developmental function of CsgA and the phenotype observed in the SocE depletion assay. CsgA exhibits remarkable similarity with short chain alcohol dehydrogenases (Lee et al. 1995), which have a core of conserved catalytic residues (Persson et al. 1991). The csgA1098 allele produces a protein (T6A) that is unable to bind $\mathrm{NAD}^{+}$in vitro and unable to restore development to $\operatorname{csg} A$ mutants when added exogenously (Lee et al. 1995). SocE depletion in the presence of this allele, or in the presence of two other alleles with mutations in the coenzyme binding region [csgA1099 (R10A) and $\operatorname{csg} A 1152$ (D57N) (Lee et al. 1995)], does not arrest growth or induce sporulation in SocE-depleted cells (data not shown). S135 and K155 are essential for catalytic activity in all known members of this family. Amino acid substitutions S135T (csgA1153) and K155R (csgA1155) fail to arrest growth or induce sporulation in SocE-depleted cells (data not shown). Three other $\operatorname{csg} A$ alleles that inhibit development also prevent growth arrest and sporulation in SocE-depleted cells including csgA653 (A157V), csgA269 (Tn5 lac insertion), and $\operatorname{csg} A 278$ (Tn5 lac insertion). These results have separated C-signaling from CsgA enzyme activity and argue that growth arrest and spore induction are mediated by internal CsgA.

\section{Suppression of growth arrest}

One can isolate pseudorevertants that are restored for growth by simply plating SocE-depleted cells on growth medium in the dark. The spontaneous reversion frequency is $\sim 3 \times 10^{-9}$ revertants/cell, suggesting that mutation of only a few genes can restore growth. Eleven independent suppressors were isolated, eight following Tn5-132 mutagenesis and three following UV mutagenesis. Because RelA and CsgA are already known to be required for growth arrest, we examined whether growth arrest could be restored by addition of functional relA or $\operatorname{csg} A$ genes to the pseudorevertants. Eight were complemented by $\operatorname{csg} A$ and three were complemented by relA. Southern hybridization confirmed that LS2133 and LS2134 contain Tn5 insertions in relA and that L2130, LS2131, LS2132, LS2135, LS2136, and LS2137 contain Tn5 insertions in $\operatorname{csg} A$ (data not shown). Finally, inverse PCR was performed on chromosomal DNA from each of the relA-complemented strains using Tn5-specific primers. The resultant PCR products were cloned and sequenced to define the precise insertion sites in relA. The insertion sites predicted by Southern hybridization were confirmed by the results of the PCR analysis (data not shown). 


\section{Developmental (p)ppGpp levels}

We wondered whether the purpose of the CsgA-dependent stringent response was to maintain cells in a growth-arrested state as a means of diverting the A-signal amino acids into developmental macromolecular synthesis. This hypothesis predicts that $\operatorname{csg} A$ mutants are unable to sustain the stringent response through the period of A-signaling and the cells consequently revert to vegetative growth. The guanine nucleotide pools of $\operatorname{csg} A$ mutant LS523 were examined during development and compared to those of wild-type strain DK1622 and a $\operatorname{csg} A$ socE double mutant (LS537). The $\operatorname{csg} A$ mutant initiated the stringent response following nutrient deprivation although the (p)ppGpp pools were only half those of the wild type. These results show that $\operatorname{csg} A$ is not essential for the stringent response following amino acid limitation and confirm the qualitative study of LaRossa et al. (1983). Most strikingly, $\operatorname{csg} A$ mutants were unable to sustain the response; the (p)ppGpp pool decreases to vegetative levels by $24 \mathrm{hr}$ (Fig. 5). Both the attenuated response and the decline to vegetative levels are consistent with the notion that $\operatorname{csg} A$ mutants do not divert A-signal amino acids to developmental macromolecular synthesis. This notion is supported by the observation that $\operatorname{csg} A$ developmental gene expression arrests during the period of A-signaling $\sim 6 \mathrm{hr}$ into the developmental pathway (Kroos and Kaiser 1987).

The socE mutation compensates for the $\operatorname{csg} A$ mutation by increasing the concentration of stringent nucleotides and sustaining the stringent response throughout development (Fig. 5). Interestingly the $\operatorname{soc} E \operatorname{csg} A$ mutant develops significantly faster than the wild type (E.W. Crawford and L.J. Shimkets, in prep.) which is correlated with higher levels of (p)ppGpp. These results suggest that SocE attenuates the stringent response.

\section{Discussion}

Because fruiting body development is an alternative to growth, most of the genetic work with $M$. xanthus has involved isolating developmental mutants that necessarily grow well. This strategy has been enormously successful but would not reveal those regulatory genes that commit a cell to the vegetative pathway, as mutations in genes that repress development would be expected to induce sporulation in rich media. We have identified the first repressor of development-SocE. SocE depletion in otherwise wild-type cells leads to growth arrest, inhibition of DNA and stable RNA synthesis, production of (p)ppGpp, and induction of sporulation in liquid growth media.

Curiously, SocE depletion initiates a RelA-dependent stringent response in the presence of extracellular amino acids. The results are consistent with the idea that the relative levels of SocE and CsgA determine cell fate during times when amino acid levels become an unreliable indicator of environmental resources. The catabolism of proteins to fuel development may fool the cell into resuming growth unless growth is arrested. This rationale is based on work done on the stringent response and A-signaling, which precede C-signaling during development. During the initial response to amino acid limitation, cells induce a RelA-dependent stringent response and accumulate (p)ppGpp (Manoil and Kaiser 1980a,b; Singer and Kaiser 1995; Harris et al. 1998). The stringent response inhibits $S O C E$ transcription (E.W. Crawford and L.J. Shimkets, in prep.), stimulates $\operatorname{csg} A$ transcription (E.W. Crawford and L.J. Shimkets, in prep.), and induces A-signaling (Singer and Kaiser 1995). A-signaling begins with the secretion of proteases that hydrolyze cell surface proteins to generate amino acids (Kuspa et al. 1992; Plamann et al. 1992). An increase in the ratio of CsgA to SocE, which is initiated by RelA-dependent transcriptional regulation of these two genes, arrests growth thereby assuring that this precious resource is used exclusively for development. Consistent with this notion, $\operatorname{csg} A$ mutants mount a developmental stringent response that is quantitatively diminished relative to the wild type and is not sustained throughout development. These results fit the temporal order of events in that
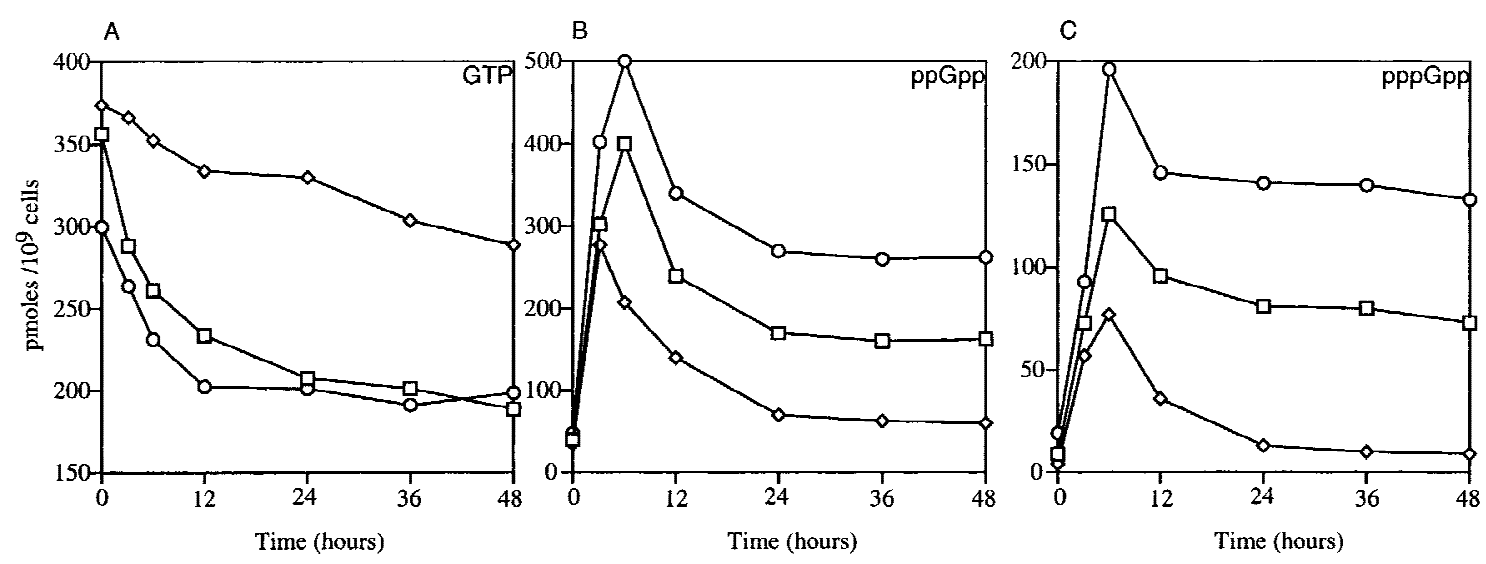

Figure 5. Guanine nucleotide pools during development. M. xanthus strains were allowed to develop in submerged culture and were harvested at the indicated times. Guanine nucleotides were extracted, separated by TLC, and quantified. Nucleotide levels are expressed as pmoles of nucleotide per $10^{9}$ cells. ( $\square$ ) wild-type DK1622; ( $\left.\diamond\right) \operatorname{csg} A$ mutant LS523; (O) $\operatorname{csg} A \operatorname{socE}$ strain LS537. 
CsgA mutants are blocked $\sim 6 \mathrm{hr}$ into the developmental program (Kroos and Kaiser 1987) during the period of A-signaling.

We propose that C-signaling involves contact-dependent exchange of CsgA as a monitor of cell density. In this model nascent CsgA is exported from the cell, both to prevent premature growth arrest and sporulation as well as to act as a cell density and alignment sensor. As cell density and alignment increase, C-signal transmission becomes more efficient (Kim and Kaiser 1990b). If extracellular CsgA is internalized while SocE is simultaneously depleted, intracellular CsgA levels would achieve levels high enough to halt growth by sustaining the stringent response throughout development and induce sporulation. If that density decreases to the point where CsgA is no longer exchanged, then the higher SocE levels would direct growth instead of development.

Because deletion of $\operatorname{soc} E$ restores development to $\operatorname{csg} A$ mutants in the absence of $\mathrm{C}$-signaling the principle function of CsgA may be to overwhelm or inhibit residual SocE. It is unlikely that CsgA directly titers out SocE to induce development, as ectopic expression of $\operatorname{csg} A$ did not stimulate development under conditions of nutrient excess where the levels of SocE are high (Li et al. 1992). The most likely possibility is that CsgA limits the level of an aminoacyl tRNA. It is likely that SocE inhibits RelA. Expression of $s o c E$ in $r e l A^{-} E$. coli leads to a rapid decline in cell viability as cells enter stationary phase (E.W. Crawford and L.J. Shimkets, in prep.). This decline in viability is greatly reduced in $r e l A^{+}$strains and can be reduced further by over expressing E. coli relA. Consistent with this suggestion is the induction of early developmental gene expression by the ectopic expression of relA under nutritional conditions that repress development via a high level of SocE (Singer and Kaiser 1995).

\section{Materials and methods}

Bacterial strains and growth conditions

E. coli and M. xanthus strains are listed in Table 2. M. xanthus cultures were grown in CYE broth ( $1 \%$ Casitone, $0.5 \%$ yeast extract, $0.1 \% \mathrm{MgSO}_{4} \cdot 7 \mathrm{H}_{2} \mathrm{O}, 10 \mathrm{~mm}$ MOPS $\left.\mathrm{pH} 7.6\right)$ or on CYE agar (CYE broth with $1.5 \%$ Difco agar) at $32^{\circ} \mathrm{C}$. When light was required, cultures were placed 4 inches below $20 \mathrm{~W}$, wide-spectrum fluorescent bulbs generating about 7000 lux. E. coli cultures were grown at $37^{\circ} \mathrm{C}$ in $\mathrm{L}$ broth. Antibiotics were used at the following concentrations: $200 \mu \mathrm{g} / \mathrm{ml}$ ampicillin; $50 \mu \mathrm{g} / \mathrm{ml}$ kanamycin; $12.5 \mu \mathrm{g} / \mathrm{ml}$ tetracycline; $250 \mu \mathrm{g} / \mathrm{ml}$ trimethoprim; for $M$. xanthus or $20 \mu \mathrm{g} / \mathrm{ml}$ for $E$. coli.

\section{Generalized transduction}

Strains were constructed by generalized transduction using Mx4 (Campos et al. 1978). relA transductants arose at a frequency several orders of magnitude lower than expected by generalized transduction in this and another study (E.W. Crawford and L.J. Shimkets, in prep.). Nevertheless, the relA mutation used in this work was confirmed by Southern hybridization (data not shown), and analyses of the guanine nucleotide pools in LS2162 confirm that it is unable to synthesize (p)ppGpp (Fig. $3)$. The reason for the reduced transduction frequency is not known. relA $A^{-}$strains were encountered regularly upon selection for growth of SocE-depleted cells.

\section{Fruiting body formation}

Log-phase cells grown in CYE broth were washed twice with TPM buffer (10 mM Tris- $\mathrm{HCl}$ at $\mathrm{pH} 8.0,8 \mathrm{~mm} \mathrm{MgSO}_{4}, 1 \mathrm{~mm}$ $\mathrm{K}_{2} \mathrm{HPO}_{4}$ ) and resuspended to $5 \times 10^{9}$ cells $/ \mathrm{ml}$ in TPM buffer. Aliquots $(20 \mu \mathrm{l})$ were spotted onto TPM agar (TPM buffer plus $1.5 \%$ Difco agar) and incubated at $32^{\circ} \mathrm{C}$. Plates were incubated at $50^{\circ} \mathrm{C}$ for $2 \mathrm{hr}$ and spores were dispersed by sonic disruption. Spores were quantified by phase-contrast microscopy in a Petroff-Hauser counting chamber. Viable spores were quantified by diluting spore preparations in TPM buffer, mixing the dilutions in CYE soft agar (CYE broth plus $0.7 \%$ Difco agar), and plating these onto CYE agar to allow spore germination.

\section{Construction of a light-inducible socE allele}

Vector pDAH328 (a gift from D. Hodgson) contains the lightinducible promoter $\mathrm{ph} v$, which is activated in the presence of blue light (Hodgson 1993). The socE gene was excised from pGC25 with FspI and NcoI to yield a socE allele that is trun-

Table 2. Strains

\begin{tabular}{|c|c|c|}
\hline Strains & Genotype & Reference or derivation \\
\hline \multicolumn{3}{|l|}{ E. coli } \\
\hline CF1648 & wild type & Cashel (1994) \\
\hline CF1651 & relA $\Delta 251$ & Cashel (1994) \\
\hline XL1 & $\begin{array}{l}\mathrm{F}^{\prime}:: \operatorname{Tn} 10, \text { pro } A^{+} B^{+}, \text {lacIq, (lacZ)M151, recA1, endA1, gyrA96, thi, hsdR17, } \\
\quad \text { supE44, relA1, lac }\end{array}$ & Bullock et al. (1987) \\
\hline \multicolumn{3}{|c|}{ 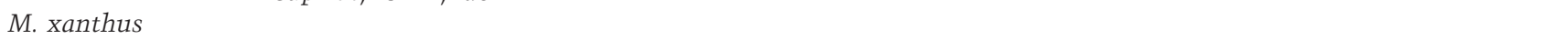 } \\
\hline DK1622 & wild type & Shimkets and Kaiser (1982a) \\
\hline LS203 & $\operatorname{csg} A 653$ & Shimkets and Asher (1988) \\
\hline LS429 & $\operatorname{csg} A 205, \Omega \mathrm{DK} 4531, \Omega \mathrm{LS} 429 \mathrm{Tp}$ & Li and Shimkets (1993) \\
\hline LS523 & $\operatorname{csg} A 205$ & Shimkets and Asher (1988) \\
\hline LS537 & csgA205, socE537 & Rhie and Shimkets (1989) \\
\hline LS2105 & $\operatorname{csg} A 653, \operatorname{soc} E 537$ & this work \\
\hline LS2125 & $\mathrm{p} h V-S O c E\left(\mathrm{Km}^{\mathrm{R}}\right)$ & this work \\
\hline LS127 & $\mathrm{ph} V-S O c E\left(\mathrm{Tc}^{\mathrm{R}}\right)$ & this work \\
\hline LS2133 & phv-socE, relA2133::Tn5-132 & this work \\
\hline LS2134 & phV-socE, relA2134::Tn5-132 & this work \\
\hline LS2162 & $\mathrm{ph} V-S O C E$, relA527 & this work \\
\hline
\end{tabular}


cated at the $3^{\prime}$ end. The NcoI end of the $1.4-\mathrm{kb}$ fragment was extended with Klenow fragment and ligated into the SmaI site of pDAH328. A plasmid containing the insert in the correct orientation was digested with XhoI and EcoRI to excise the entire phv-socE fusion, and this fragment was ligated into XhoI/ EcoRI-digested pBGS18 (Spratt et al. 1986). The resulting plasmid, pGC37, was electroporated into M. xanthus strain DK1622 in the light selecting for kanamycin resistance. Southern hybridization verified the structure of the electroporants. Specifically, chromosomal DNA from the parent, DK1622, and an electroporant was digested with FspI and PstI and probed with the 500-bp NcoI-HindIII fragment of socE. Cells containing a wildtype copy of $S O c E$ produce a 2.8 -kb fragment, whereas the merodiploid produces a $4.3-\mathrm{kb}$ fragment, as the phv-socE allele has lost the 5' FspI site during insertion of phv.

\section{Analysis of (p)ppGpp levels}

Analysis of guanine nucleotide levels was performed using a modification of the method described by Manoil and Kaiser (1980a). Cells were labeled in CYE broth containing $100 \mu \mathrm{Ci} / \mathrm{ml}$ $\left[{ }^{32} \mathrm{P}\right]$ orthophosphate and $5 \mu \mathrm{M}$ cold orthophosphate carrier for $12 \mathrm{hr}$, using light induction of $\operatorname{soc} E$ expression when necessary. After preincubation, cells were diluted to $10^{7}$ cells $/ \mathrm{ml}$ in the same medium and incubated in the light or the dark as required. For developmental studies $400 \mu$ l of CYE medium containing $100 \mu \mathrm{Ci} / \mathrm{ml}\left[{ }^{32} \mathrm{P}\right]$ orthophosphate and $5 \mu \mathrm{M}$ cold orthophosphate carrier was placed in each well of a 24-well cell culture dish and $5 \times 10^{8}$ cells added. These were incubated overnight at $32^{\circ} \mathrm{C}$ to allow biofilm formation. Biofilms were washed gently four times with MC7 buffer ( $10 \mathrm{~mm}$ MOPS, $1 \mathrm{mM} \mathrm{CaCl}_{2}$ ) and overlaid with MC7 plus $100 \mu \mathrm{Ci} / \mathrm{ml}\left[{ }^{32} \mathrm{P}\right]$ orthophosphate and $5 \mu \mathrm{M}$ cold orthophosphate carrier. An entire biofilm was harvested at each time point, and cells were centrifuged and resuspended in $50 \mu \mathrm{l}$ of MC7 buffer. Each sample was mixed with $50 \mu \mathrm{l}$ of $13 \mathrm{M}$ formic acid. Guanine nucleotides were released by two freezethaw cycles and separated by one-dimensional TLC on PEI cellulose plates (Sigma) with $1.5 \mathrm{M} \mathrm{KH}_{2} \mathrm{PO}_{4}$ (Cashel 1994). Spots were visualized and quantified using a PhosphorImager 400S (Molecular Dynamics) and ImageQuant version 1.0 (Molecular Dynamics).

\section{Electron microscopy}

Spores were purified on sucrose step gradients (Inouye et al. 1979) and prepared as described previously (Shimkets and Kaiser 1982b). Spores were embedded in Spurr resin, and thin sections were cut with a Sorvall MT2-B Ultra Microtome and viewed with a Jeol $100 \mathrm{CX}$ transmission electron microscope.

\section{DNA and RNA synthesis}

Strains were grown in CYE broth with light to mid-log phase. These cultures were then diluted into fresh CYE broth containing $25 \mu \mathrm{Ci} / \mathrm{ml}\left[{ }^{3} \mathrm{H}\right]$ uridine (Amersham) for measuring RNA synthesis or $25 \mu \mathrm{Ci} / \mathrm{ml}\left[{ }^{3} \mathrm{H}\right]$ thymidine for measuring DNA synthesis. Upon transfer to the labeling medium, cultures were wrapped in foil. Growth of these cultures was followed using a Klett meter and 200- $\mu$ l samples were removed for analysis at intervals for $24 \mathrm{hr}$. Samples were mixed with $600 \mu \mathrm{l}$ of ice cold $10 \%$ TCA and filtered through Whatman GF/A glass fiber filters. Filters were washed three times each with $2 \mathrm{ml}$ of ice-cold $10 \%$ TCA and once with $2 \mathrm{ml}$ of ice-cold $100 \%$ ethanol. Filters were dried and counted in a liquid scintillation counter.

\section{Measurement of socE $m R N A$}

Cells were grown in $100 \mathrm{ml}$ of CYE broth in the light. Dark- grown cultures were wrapped in foil in the same incubator. Five-milliliter aliquots were harvested by centrifugation (10 min at $7800 \mathrm{~g}$ ). Pellets were frozen until sampling was completed. Pellets were then thawed on ice and resuspended in $5 \mathrm{ml}$ of protoplasting buffer ( $15 \mathrm{~mm}$ Tris- $\mathrm{HCl}$ at $\mathrm{pH} 8.0,0.45 \mathrm{M}$ sucrose, $8 \mathrm{~mm}$ EDTA). To this was added $40 \mu \mathrm{l}$ of $50 \mathrm{mg} / \mathrm{ml}$ lysozyme and samples were incubated on ice for $15 \mathrm{~min}$. Protoplasts were collected by centrifugation ( $5 \mathrm{~min}$ at $3800 \mathrm{~g}$ ). Samples were then resuspended in $0.5 \mathrm{ml}$ of lysing buffer $(10 \mathrm{~mm}$ Tris- $\mathrm{HCl}$ at $\mathrm{pH}$ 8.0, $10 \mathrm{~mm} \mathrm{NaCl}, 1 \mathrm{~mm}$ Na-citrate, $1.5 \%$ SDS) and $15 \mu \mathrm{lof}$ dimethylpyrocarbonate. Samples were mixed gently and incubated for $5 \mathrm{~min}$ at $37^{\circ} \mathrm{C}$. Protein was precipitated by chilling on ice, adding $250 \mu \mathrm{l}$ of saturated $\mathrm{NaCl}$, incubating for $10 \mathrm{~min}$ on ice, and centrifuging for $10 \mathrm{~min}$. RNA was ethanol precipitated overnight at $-20^{\circ} \mathrm{C}$, washed with $80 \%$ ethanol, dried, and resuspended in $100 \mu \mathrm{l}$ of $\mathrm{dH}_{2} \mathrm{O}$. RNA was quantified on a spectrophotometer at $260 \mathrm{~nm}$ and $1.0 \mu \mathrm{g}$ was loaded onto a slot blot. The membranes were probed with a digoxigenin-labeled AccI$H$ HindIII DNA fragment from the socE gene (E.W. Crawford and L.J. Shimkets, in prep.).

\section{Pseudorevertant analysis}

Pseudorevertants of LS2125 that grow following SocE depletion were induced by UV light or Tn5-132 insertion. For UV mutagenesis, an exponentially growing LS2125 culture was pelleted and resuspended in TM buffer $(10 \mathrm{~mm}$ Tris at $\mathrm{pH} 7.6,1 \mathrm{~mm}$ $\mathrm{MgSO}_{4}$ ) to a final cell density of $10^{9}$ cells $/ \mathrm{ml}$. The cell suspension was exposed to UV light at $1500 \mu \mathrm{W} / \mathrm{cm}^{2}$ for $15 \mathrm{sec}$ with a germicidal UV lamp, killing 95\%-99\% of the cells. The mutagenized cells were diluted 1:10 in CYE broth plus $50 \mu \mathrm{g} / \mathrm{ml}$ kanamycin and aliquoted into $2-\mathrm{ml}$ pools that were incubated in the dark. Pools were examined for turbidity at 12-hr intervals. Turbid cultures were streaked for isolation on CYE agar, and one-well isolated colony was saved from each pool. UV-induced pseudorevertants were isolated at a frequency of $\sim 1.6 \times 10^{-7}$.

Transposon-induced pseudorevertants were isolated by infecting LS2125 with P1 Tn5-132 (Kuner and Kaiser 1981). P1 Tn5-132 was mixed with $10^{8}$ cells at a MOI of 1.0. After 20 min the mixture was spread onto CYE agar containing $8 \mu \mathrm{g} / \mathrm{ml}$ oxytetracycline and incubated in the dark. Plates were overlaid with oxytetracycline $12 \mathrm{hr}$ later to a final concentration of 20 $\mu \mathrm{g} / \mathrm{ml}$.

Pseudorevertants were examined for the ability of $\operatorname{csg} A^{+}$or relA $A^{+}$to restore growth arrest upon SocE depletion. pGC65, a trimethoprim-resistant derivative of the integrative vector pLJS60 (Li and Shimkets 1988), was constructed by digesting chromosomal DNA from LS429, a strain of $M$. xanthus containing a Tn5-Tp (Sasakawa and Yoshikawa 1987) insertion, with EcoRI and HindIII. A $2.0-\mathrm{kb}$ fragment containing the trimethoprim-resistance marker was ligated into the HindIIIEcoRI site of pLJS60. The ligation was electroporated into E. coli XLI, selecting trimethoprim resistance. The resulting plasmid was digested with HindIII, mixed with either a $3.9-\mathrm{kb}$ HindIII fragment from pLJS69 (Shimkets and Rafiee 1990) that contains $\operatorname{csg} A$ (yielding pGC66) or a $2.7-\mathrm{kb}$ HindIII fragment from pMS132 (Harris et al. 1998) that contains E. coli relA under control of $\mathrm{phv}$ (yielding pGC67).

The $\operatorname{csg} A$-containing plasmid (pGC66) was electroporated into each of the pseudorevertants, selecting trimethoprim resistance, on CYE agar plus $250 \mu \mathrm{g} / \mathrm{ml}$ trimethoprim in the light. Electroporants were grown in CYE broth in the light in the presence of trimethoprim and shifted to the dark, and their growth monitored. The three pseudorevertants that were not complemented by $\operatorname{csg} A$ were electroporated with the $r e l A$ plasmid pGC67, selecting trimethoprim resistance in the light. 
Electroporants were grown in CYE broth in the light before being shifted to the dark.

Southern hybridization confirmed that LS2133 and LS2134 contain Tn5 insertions in relA and that L2130, LS2131, LS2132, LS2135, LS2136, and LS2137 contain Tn5 insertions in csgA (data not shown). Inverse PCR was performed on chromosomal DNA from two of the relA-complemented strains using Tn5specific primers. The resultant PCR products were cloned and sequenced to define the precise insertion sites in relA. DNA flanking the Tn5-132 insertions in pseudorevertants LS2133 and LS2134 was cloned by inverse PCR (Ochman et al. 1988) using Tn5 specific primers GGTTCCGTTCAGGACGCTAC and GGTGATCCTCGCCGTACTGC. The resulting 310-bp (from LS2133) and 260-bp (from LS2134) products were cloned into pUC19 and sequenced.

\section{Acknowledgments}

This work was supported by NSF grant MCB9601077. We thank C. Kelloes and M. Farmer for help with the electron microscopy. We also thank K. O'Connor, D. Zusman, M. Cashel, M. Singer, and $\mathrm{D}$. Hodgson for providing strains used in this work. We are grateful to D. Kearns and R. Phillips for critical reading of this manuscript.

The publication costs of this article were defrayed in part by payment of page charges. This article must therefore be hereby marked "advertisement" in accordance with 18 USC section 1734 solely to indicate this fact.

\section{References}

Bullock, W.O., J.M. Fernandez, and J.M. Short. 1987. XL1-Blue: A high efficiency plasmid transforming recA Escherichia coli strain with beta-galactosidase selection. Biotechniques 5: 376-379.

Campos, J.M., J. Geisselsoder, and D.R. Zusman. 1978. Isolation of bacteriophage MX4, a generalized transducing phage for Myxococcus xanthus. J. Mol. Biol. 119: 167-178.

Cashel, M. 1994. Detection of (p)ppGpp accumulation patterns in Escherichia coli mutants. In Methods in molecular genetics (ed. K.W. Dolph), pp.341-356. Academic Press, San Diego, CA.

Cashel, M., D. Gentry, J. Hernandez, and D. Vinella. 1996. The stringent response. In Escherchia coli and Salmonella: Cellular and molecular biology (ed. F.C. Neidhart), pp. 1458 1496. ASM Press, Washington, D.C.

Downard, J., S.V. Ramaswamy, and K.-S. Kil. 1993. Identification of esg, a genetic locus involved in cell-cell signaling during Myxococcus xanthus development. I. Bacteriol. 175: 7762-7770.

Dworkin, M. 1996. Recent advances in the social and developmental biology of the myxobacteria. Microbiol. Rev. 60: 70102.

Dworkin, M. and S.M. Gibson. 1964. A system for studying microbial morphogenesis: Rapid formation of microcysts in Myxococcus xanthus. Science 146: 243-244.

Dworkin, M. and D.J. Niederpruem. 1964. Electron transport system in vegetative cells and microcysts of Myxococcus xanthus. J. Bacteriol. 87: 316-322.

Gollop, R., M. Inouye, and S. Inouye. 1991. Protein U, a latedevelopmental spore coat protein of $M$. xanthus, is a secre- tory protein. J. Bacteriol. 173: 3597-3600.

Hagen, D.C., A.P. Bretscher, and D. Kaiser. 1978. Synergism between morphogenetic mutants of Myxococcus xanthus. Devel. Biol. 64: 284-296.

Harris, B.Z., D. Kaiser, and M. Singer. 1998. The guanosine nucleotide (p)ppGpp initiates development and A-factor production in Myxococcus xanthus. Genes \& Dev. 12: 10221035.

Hodgson, D.A. 1993. Light-induced carotenogenesis in Myxococcus xanthus: Genetic analysis of the carR region. Mol. Microbiol. 7: 471-488.

Inouye, M., S. Inouye, and D. R. Zusman. 1979. Biosynthesis and self-assembly of protein $S$, a development-specific protein of Myxococcus xanthus. Proc. Nat1. Acad. Sci. 76: 209213.

Kaiser, D. 1996. Bacteria also vote. Science 272: 1598-1599.

Kim, S.K. and D. Kaiser. 1990a. C-factor: A cell-cell signaling protein required for fruiting body morphogenesis of Мухоcoccus xanthus. Cell 61: 19-26.

- 1990b. Cell alignment required in differentiation of $M$. xanthus. Science 249: 926-928.

- 1991. C-Factor has distinct aggregation and sporulation thresholds during Myxococcus development. J. Bacteriol. 173: $1722-1728$.

Kroos, L. and D. Kaiser. 1987. Expression of many developmentally regulated genes in Myxococcus depends on a sequence of cell interactions. Genes \& Dev. 1: 840-854.

Kuner, J.M. and D. Kaiser. 1981. Introduction of transposon Tn5 into Myxococcus for analysis of developmental and other nonselectable mutants. Proc. Natl. Acad. Sci. 78: 425-429.

Kuspa, A., L. Plamann, and D. Kaiser. 1992. Identification of heat-stable A-factor from Myxococcus xanthus. J. Bacteriol. 174: 3319-3326.

LaRossa, R., J. Kuner, D. Hagan, C. Manoil, and D. Kaiser. 1983. Developmental cell interactions of Myxococcus xanthus: Analysis of mutants. J.Bacteriol. 153: 1394-1404.

Lee, B.-U., K. Lee, J. Mendez, and L.J. Shimkets. 1995. A tactile sensory system of Myxococcus xanthus involves an extracellular NAD $(\mathrm{P})^{+}$-containing protein. Genes \& Dev. 9: 29642973.

Li, S. and L.J. Shimkets. 1988. Site-specific integration and expression of a developmental promoter in Myxococcus xanthus. J. Bacteriol. 170: 5552-5556.

Li, S.F. and L.J. Shimkets. 1993. Effect of dsp mutations on the cell-to-cell transmission of CsgA in Myxococcus xanthus. J. Bacteriol. 175: 3648-3652.

Li, S., B. Lee, and L.J. Shimkets. 1992. csgA expression entrains Myxococcus xanthus development. Genes \& Dev. 6: 401410.

Manoil, C. and D. Kaiser. 1980a. Accumulation of guanosine tetraphosphate and guanosine pentaphosphate in Myxococcus xanthus during starvation and myxospore formation. $J$. Bacteriol. 141: 297-304.

- 1980b. Guanosine pentaphosphate and guanosine tetraphosphate accumulation and induction of Myxococcus xanthus fruiting body development. J. Bacteriol. 141: 305-315.

- 1980c. Purine-containing compounds, including cyclic adenosine 3',5'-monophosphate, induce fruiting of Мухоcoccus xanthus by nutritional imbalance. I. Bacteriol. 141: 374-377.

McCleary, W.B. Esmon, and D. Zusman. 1991. M. xanthus protein $\mathrm{C}$ is a major spore surface protein. I. Bacteriol. 173: 2141-2145.

Ochman, H., A.S. Gerber, and D.L. Hartl. 1988. Genetic applications of an inverse polymerase chain reaction. Genetics 120: $621-623$. 
O'Connor, K. and D. Zusman. 1991a. Development in M. xanthus involves differentiation into two cell types, peripheral rods and spores. J. Bacteriol. 173: 3318-3333.

- 1991b. Behavior of peripheral rods and their role in the life cycle of M. xanthus. J. Bacteriol. 173: 3342-3355.

Otani, M. S. Kozaku, C. Xu, C. Umezawa, K. Sano, and S. Inouye. 1998. Protein W, a spore-specific protein in Myxococcus xanthus, formation of a large electron-dense particle in a spore. Mol. Microbiol. 30: 57-66.

Persson, B., M. Krook, and H. Jornvall. 1991. Characteristics of short-chain alcohol dehydrogenases and related enzymes. Eur. J. Biochem. 200: 537-543.

Plamann, L. and H.B. Kaplan. 1999. Cell-density sensing during early development in Myxococcus xanthus. In Cell-cell signaling in bacteria (ed. D.M. Dunny and S.C. Winans), pp. 67-82. ASM Press, Washington, D.C.

Plamann, L., A. Kuspa, and D. Kaiser. 1992. Proteins that rescue A-signal-defective mutants of Myxococcus xanthus. J. Bacteriol. 174: 3311-3318.

Ramsey, W.S. and M. Dworkin. 1968. Microcyst germination in Myxococcus xanthus. J. Bacteriol. 95: 2249-2257.

Rhie, H.G. and L.J. Shimkets. 1989. Developmental bypass suppression of Myxococcus xanthus csgA mutations. J. Bacteriol. 171: 3268-3276.

Sager, B. and D. Kaiser. 1994. Intercellular C-signaling and the traveling waves of Myxococcus. Genes \& Dev. 8: 2793-2804.

Sasakawa, C. and M. Yoshikawa. 1987. A series of Tn5 variants with various drug-resistance markers and suicide vector for transposon mutagenesis. Gene 56: 283-288.

Shimkets, L.J. 1999. Intercellular signaling during fruiting-body development of Myxococcus xanthus. Ann. Rev. Microbiol.53: 525-49.

Shimkets, L.J. and S.J. Asher. 1988. Use of recombination techniques to examine the structure of the csg locus of Мyxococcus xanthus. Mol. \& Gen. Genet. 211: 63-71.

Shimkets, L.J. and D. Kaiser. 1982a. Induction of coordinated movement of Myxococcus xanthus cells. I. Bacteriol. 152: 451-461.

-1982b. Murein components rescue developmental sporulation of Myxococcus xanthus. J. Bacteriol. 152: 462 470.

- 1999. Cell contact-dependent C signaling in Myхососcus xanthus. In Cell-cell signaling in bacteria (ed. D.M. Dunny and S.C. Winans), pp. 83-100. ASM Press, Washington, D.C.

Shimkets, L. and H. Rafiee. 1990. CsgA, an extracellular protein essential for M. xanthus development. J. Bacteriol. 172: 52995306.

Singer, M. and D. Kaiser. 1995. Ectopic production of guanosine penta- and tetraphosphate can initiate early developmental gene expression in Myxococcus xanthus. Genes \& Dev. 9: $1633-1644$.

Sogaard-Anderson, L. and D. Kaiser. 1996. C factor, a cell-surface-associated intercellular signaling protein, stimulates the cytoplasmic Frz signal transduction system in Myxососcus xanthus. Proc. Natl. Acad. Sci. 93: 2625-2679.

Spratt, B.G., P.J. Hedge, S.T. Heesey, A. Edelman, and J.K. Broome-Smith. 1986. Kanamycin-resistant vectors that are analogues of pUC8, pUC9, pEMBL8 and pEMBL9. Gene 41: 337-342.

Wireman, J.W. and M. Dworkin. 1975. Morphogenesis and developmental interactions in myxobacteria. Science 189: 516522 .

- 1977. Developmentally induced autolysis during fruiting body formation by Myxococcus xanthus. I. Bacteriol. 129: 796-802.
Zusman, D. and E. Rosenberg. 1970. DNA cycle of Myxococcus xanthus. J. Mol. Biol. 49: 609-619.

- 1971. Division cycle of Myxococcus xanthus-II. Kinetics of stable and unstable RNA synthesis. J. Bacteriol. 105: 801810. 


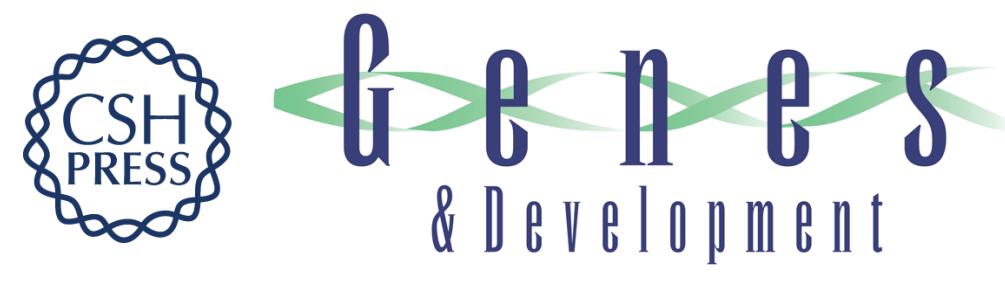

\section{The stringent response in Myxococcus xanthus is regulated by SocE and the CsgA C-signaling protein}

Eugene W. Crawford, Jr. and Lawrence J. Shimkets

Genes Dev. 2000, 14:

Access the most recent version at doi:10.1101/gad.14.4.483

References This article cites 49 articles, 34 of which can be accessed free at: http://genesdev.cshlp.org/content/14/4/483.full.html\#ref-list-1

License

Email Alerting Receive free email alerts when new articles cite this article - sign up in the box at the top Service right corner of the article or click here.

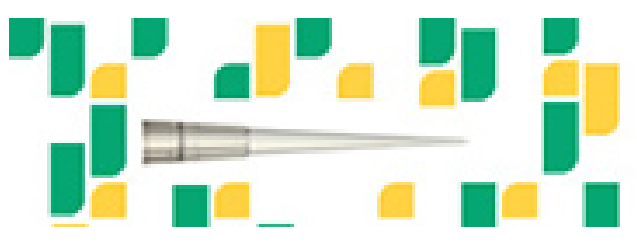

Focused on your science. 